\title{
Diagnosis of Penile Cancer
}

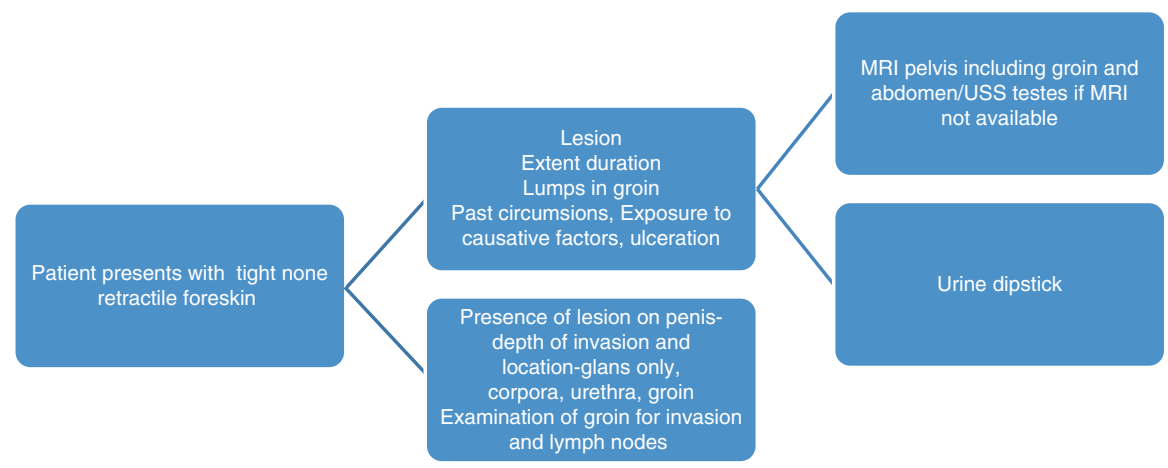

\section{Suggested Reading}

Håkansson U, Kirrander P, Uvelius B, Baseckas G, Torbrand C. Organ-sparing reconstructive surgery in penile cancer: initial experiences at two Swedish referral centres. Scand J Urol. 2015;49(2):149-54.

Hakenberg OW, Compérat E, Minhas S, Necchi A, Protzel C, Watkin N, Guidelines Associate: Robinson R. EAU guidelines on penile cancer: 2014 update. Eur Urol. 2015;67(1):142-50.

Shabbir M, Kayes O, Minhas S. Challenges and controversies in the management of penile cancer. Nat Rev Urol. 2014;11(12):702-11. 